\title{
DRIVING SPEED INFLUENCE ON OPERATOR VIBRATION EXPOSURE IN FORWARDING OPERATIONS
}

\author{
Gediminas Vasiliauskas, Ricardas Butkus, Remigijus Zinkevicius \\ Vytautas Magnus University, Lithuania \\ gediminas.vasiliauskas@vdu.lt, ricardas.butkus@vdu.lt, remigijus.zinkevicius@vdu.lt
}

\begin{abstract}
Mechanized forest works, especially cut-to-length operations, have spread widely over the last decades. Operation of harvesters and forwarders is related with increased productivity compared with manual cutting, generally better working conditions for operators, but it also might have some negative aspects. As the productivity of forwarders depends strongly on the transportation distance to unloading location, forest road conditions, log density on site, there are efforts of the drivers and contractors to work more efficiently and to achieve better productivity. As the operation with the crane depends strongly on the operator's skills and log density, there are limited possibilities to make improvements. Therefore, operators attempt to increase the driving speed still acceptable to achieve the highest possible performance. However, this usually leads to increased operator vibrations. The aim of this study was to justify the forwarder driving speed of full and empty travel, which could ensure best productivity results with the lowest whole-body vibration exposure on the operator. The research was carried on the typical forest road, where the empty and full transport was carried out at speeds ranging from 5 to $15 \mathrm{~km} \cdot \mathrm{h}-1$. The results show that optimum speed for empty and full travel operations was approx. $8 \mathrm{~km} \cdot \mathrm{h}-1$. At this speed the daily exposure value standardised to an eight-hour reference period $A(8)$ would be less than $0.5 \mathrm{~m} \cdot \mathrm{s}-$ 1 for full transport operations and $\sim 0.57 \mathrm{~m} \cdot \mathrm{s}-1$ for empty transport for total $10 \mathrm{~km}$ driving distance.
\end{abstract}

Keywords: forwarder, whole-body vibration.

\section{Introduction}

Forwarder driving speed is one of the most important factors influencing the productivity of the forest machines, so it should be selected appropriately when optimizing the forwarding roads and trying to seek maximum performance [1]. Usually, the driving speed is selected by the operator and is related to the road conditions, load of the machine, the terrain of the site, the distance from the log piles to the loading location and the subjective operator perception. Generally, forwarder driving can be divided into two phases: 1) driving on strip road and 2) driving on haul road. For the long forwarding distances the ratio of the driving on the haul road tends to increase, therefore the driving speed also increases. Interesting findings were found by Kumazawa [2] and confirmed by Berg [1] that driving distance is the crucial factor on the driving speed of the forwarder, which is mostly related with operator's mental stress that longer forwarding is directly related with lower productivity. This is the main reason why the operators of the machine try to increase the driving speed, especially for the empty transport operations. These results agree with the results of other studies [3;4], where a typical time structure of full travel ranges from 6 to 22 percent, while it is from 7 to 15 percent for empty travel. This distribution shows that the same distance is travelled up to 7 percent faster with empty machine. Similar results were also found in the productivity study performed by Strandgard et. al., where they found the distribution of $29 \%$ for loaded empty and loaded operations and concluded that travel speed, distance and terrain are determining factors for productivity [6].

Mechanized forwarding is also investigated from other perspectives including the operator comfort in forwarding operations. Killen and Eger [7] excluded 3 types of factors, which have influence on forwarder operator whole body vibration exposure. These factors include 1) vehicle factors, 2) environment factors and 3) operator factors. As environment factors in the site cannot be changed easily (forwarding distance, terrain, condition, and smoothness of the road etc.), forwarder manufacturers usually seek for technical means for the operator comfort improvement, such as design of the cab, seat, and chassis suspension systems to reduce the negative effects on the operator [8]. As sitting for prolonged periods of time can cause low back pain problems, the behaviour of the operator is crucial for vibration exposure. This was approved by Rehn et al. in [9], where they stated that crucial factors on WBV are the forwarder model and the operator's behaviour. The selection of the sitting position, adjustment of the seat, substitution of the sitting postures and the selection of the comfortable driving speed are also critical factors on the operator's vibration exposure.

Rehn et al. [9] investigated the exposure to whole-body vibration of the forwarder operators and found that the vibration risk on operators depends on the intensity and duration of the vibration in 
forwarding operations. It was reported in multiple studies [3-5; 9] that operator's whole body vibration risk is the highest in full and empty forwarding operations. Additionally to thevibration level, the time factor is important on total exposure of the operator. In the study of Rehn [9] it was found that average vibration total value (VTV) was $1.69 \pm 0.6 \mathrm{~m} \cdot \mathrm{s}^{-2}$ (empty transport) and $1.1 \pm 0.53 \mathrm{~m} \cdot \mathrm{s}^{-2}$ (loaded transport). Very similar results were also found in the study of Poje [3], where the unloaded transport RMS VTV acceleration was $1.28 \mathrm{~m} \cdot \mathrm{s}^{-2}$ and $1.04 \mathrm{~m} \cdot \mathrm{s}^{-2}$ for loaded transport. Vibration acceleration values for loading and unloading were below the $0.5 \mathrm{~m} \cdot \mathrm{s}^{-2}$ threshold. However, as the percentage of full and empty travel can consist of up to 37 percent in the wood extraction cycle (especially for long distances), it becomes obvious that these operations are crucial on the operator vibration exposure.

There are little data of the speed influence on the operator's vibration exposure and on the acceleration values in full and empty transport operations. As the speed increases, it has a positive effect on the forwarder productivity, operators usually try driving as fast as possible under the present condition, especially at long transportation distances. This significantly affects the RMS VTV and the total exposure.

The aim of this study was to determine the optimum driving speed for empty and full forwarding operations and to predict its influence on the operator vibration exposure $A(8)$.

\section{Materials and methods}

\section{Location and conditions}

Field study was carried out in the forest compartment located in in Eastern Carpathians, Harghita county, Romania. Measurements were carried out with the experimental machine, which was a new eight-wheel driven HSM 208F forwarder prototype. The driver seat was adjusted to the weight of the operator, which was $\sim 820 \mathrm{~N}$. The net weight of the machine was 16 tons and the typical tire pressure of 3.5 psi for front and 3.8 for the rear axle tires. Measurements were carried out in a forest road (haul road) covered with argillite stones covered with a layer of mud. A view of the road surface condition is given below in Fig. 1.

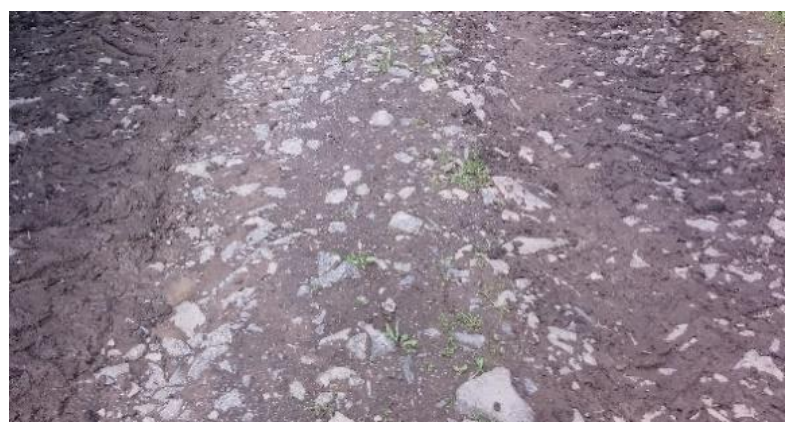

Fig. 1. General view of the forest road condition

The research included the measurement of WBV under multiple conditions. Before the measurement, a test drive was performed to determine the driving speed, which would be typical for these conditions. The operator reported that typical driving speed would be $10 \mathrm{~km} \cdot \mathrm{h}^{-1}$. Taking this speed as a reference, the experimental design was set up. Driving speed on the road was selected from 7.5 to $15 \mathrm{~km} \cdot \mathrm{h}^{-1}$ in the steps of $2.5 \mathrm{~km} \cdot \mathrm{h}^{-1}$. The speed was manually controlled by the operator. Measurements were carried out for loaded and unloaded forwarder. The load was always the same, i. e. 20 cubic meters of spruce for full transport operations. Measurements were started manually at starting and ending points of the road, which was of the total length 350 meters.

\section{Vibration measurement and evaluation}

Whole body vibration measurements were carried out according to the requirements provided in ISO 2631-1 [10] and typical for operator WBV evaluation. Vibration acceleration values were collected using the human vibration analyser Bruel\&Kjaer type 4447 with the seat pad accelerometer type 4524B. The seat pad accelerometer was put on the seat of the operator, oriented as given in the ISO standard and connected to the hand-held vibration analyser (Fig. 2). Measurement results, which were the logged 
as RMS $\mathrm{x}, \mathrm{y}$, and $\mathrm{z}$ acceleration values, were later used for the calculations of the vibration exposure $A(8)$ at different driving speeds. Duration of the measurement differed under different driving speeds and was on average $126 \pm 12 \mathrm{~s}$.

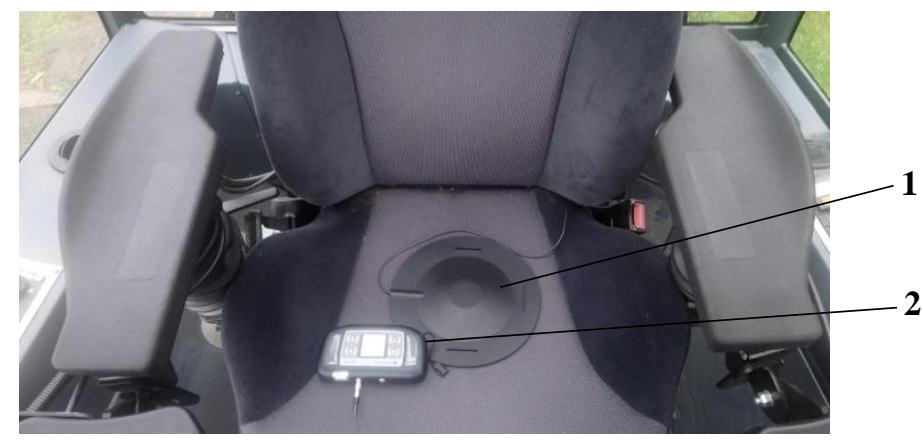

Fig. 2. Whole body vibration measurement instrumentation: 1 - seat pad accelerometer;

2 -Bruel\&Kjaer type 4447 human vibration analyser

WBV evaluation was done assessing the frequency weighted RMS values $\left(a_{w}\right)$ in three orthogonal direction $x, y$ and $z$. The RMS magnitudes were calculated as provided in ISO 2631-1 [10] and given in equation 1:

$$
a_{w}=\sqrt{\left[\frac{1}{T} \int_{0}^{T} a_{w}^{2}(t) d t\right]},\left[\mathrm{m} \cdot \mathrm{s}^{-2}\right]
$$

where $a_{w}(t)$ - weighted acceleration as a time function, $\mathrm{m} \cdot \mathrm{s}^{-2}$;

$T$ - duration of the measurement, s.

Product of the sum of the vibration magnitudes $a_{w, x}, a_{w, y}$ and $a_{w, z}$ gives the vibration total value VTV $\left(a_{v}\right)$, which is calculated by applying the correction factors $k_{x, y, z}$ for all vibration directions. Vibration total value was then calculated as follows:

$$
a_{v}=\sqrt{k_{x}^{2} a_{w x}^{2}+k_{y}^{2} a_{w y}^{2}+k_{z}^{2} a_{w z}^{2}},\left[\mathrm{~m} \cdot \mathrm{s}^{-2}\right]
$$

where $k_{x}, k_{y}, k_{z}$ - sensitivity factors in orthogonal axis ( $x-1,4 ; y-1,4$ and $z-1$ respectively); $a_{w, x}, a_{w, y}, a_{w, z}$ - measured vibration acceleration in $x, y, z$ axis, $\mathrm{m} \cdot \mathrm{s}^{-2}$.

Vibration exposure evaluation was carried out according to the exposure values provided in the EU Directive 2002/44/EC [11]. According to the directive, exposure values are fixed at $0.5 \mathrm{~m} \cdot \mathrm{s}^{-2}$ (exposure action value) and $1.15 \mathrm{~m} \cdot \mathrm{s}^{-2}$ (exposure limit value).

Vibration exposure is typically calculated as the time weighted sum of accelerations in different operations. The object of analysis in our study was the determination of optimum speed in respect with lowest possible exposure. Calculation was performed as follows:

$$
A(8)=\sqrt{\frac{1}{480}\left(a_{w i}^{2} T_{i}\right)},
$$

where $a_{w i}$ - frequency weighted acceleration average during operation $I, \mathrm{~m} \cdot \mathrm{s}^{-2}$;

$T_{i}$ - duration of operation $i$, s.

The calculation of $A(8)$ was carried out in the following order. As the driving speed increases, the driving duration in the track of a fixed length reduces. Reduced driving duration should give lower value of $A(8)$, but the measured $a_{w i}$ tends to increase at higher speeds. By calculating multiple $a_{w i}$ and $T_{i}$ combinations, the optimum speed can be determined from the obtained data. From these data it is possible to select the optimum speed at which the $A(8)$ exposure value reaches the optimum value. $A(8)$ was calculated for two conditions: 1) when the total driving distance was $10 \mathrm{~km}$ and 2) when the driving distance was $20 \mathrm{~km}$ per working day. This enabled to evaluate if the optimum speed is the same for shorter and longer transport distances. 


\section{Results and discussion}

Mean vibration acceleration values for empty and full travel operations are provided in Table 1. The results show that the speed increase from 5.0 to $15 \mathrm{~km} \cdot \mathrm{h}^{-1}$ in traveling operations had increased the operator whole body vibration acceleration value RMS VTV by the factor of $\sim 2$. Additionally, full transport acceleration values in all tested cases were from 29 to 41 percent lower than for empty travel. However, the increase in the vibration total value does not show the change in vibration exposure $A(8)$ of the operator, as the speed increase reduces the time required for the transport.

Table 1

Measured and calculated values for empty and full forwarding travel operations in the total length of the reference forwarding distances of 10 and $20 \mathrm{~km}$ per working day

\begin{tabular}{|c|c|c|c|c|c|c|c|}
\hline \multirow{3}{*}{$\begin{array}{l}\text { Driving } \\
\text { speed, } \\
\mathbf{k m} \cdot \mathbf{h}^{-1}\end{array}$} & \multirow{3}{*}{$\begin{array}{c}\text { Empty travel } \\
\text { RMS VTV } \\
a_{w}, \mathrm{~m} \cdot \mathrm{s}^{-2} \\
\end{array}$} & \multirow{3}{*}{$\begin{array}{c}\text { Full travel } \\
\text { RMS VTV, } \\
\boldsymbol{a}_{w}, \mathbf{m} \cdot \mathbf{s}^{-2} \\
\end{array}$} & \multirow{3}{*}{$\begin{array}{c}\text { Increase } \\
\text { (full/empty) } \\
\%\end{array}$} & \multicolumn{2}{|c|}{$10 \mathrm{~km}$} & \multicolumn{2}{|c|}{$20 \mathrm{~km}$} \\
\hline & & & & $\begin{array}{c}\text { Empty } \\
\text { travel }\end{array}$ & $\begin{array}{c}\text { Full } \\
\text { travel }\end{array}$ & $\begin{array}{c}\text { Empty } \\
\text { travel }\end{array}$ & $\begin{array}{c}\text { Full } \\
\text { travel }\end{array}$ \\
\hline & & & & \multicolumn{4}{|c|}{$A(\mathbf{8}), \mathbf{m} \cdot \mathrm{s}^{-2}$} \\
\hline 5.0 & $1.50 \pm 0.20$ & $1.06 \pm 0.17$ & 29.1 & 0.61 & 0.51 & 0.86 & 0.73 \\
\hline 7.5 & $1.83 \pm 0.49$ & $1.23 \pm 0.32$ & 32.9 & 0.55 & 0.45 & 0.78 & 0.64 \\
\hline 10.0 & $2.94 \pm 0.38$ & $1.73 \pm 0.24$ & 41.1 & 0.61 & 0.47 & 0.86 & 0.66 \\
\hline 12.5 & $2.99 \pm 0.47$ & $1.86 \pm 0.29$ & 37.8 & 0.55 & 0.43 & 0.77 & 0.61 \\
\hline 15.0 & $2.83 \pm 0.1$ & $2.01 \pm 0.27$ & 29.1 & 0.49 & 0.41 & 0.69 & 0.58 \\
\hline
\end{tabular}

From the measured data the vibration exposure of operator was calculated. As the driving speed has a crucial role on productivity, especially when the loading site is far from the unload location, operators usually try to drive as fast as possible and as reasonable. The calculation results of $A(8)$ for shorter $(10 \mathrm{~km})$ and longer $(20 \mathrm{~km})$ total working day travelling distances reveal the fact that longer driving gives higher exposure values. This means that higher acceleration values at higher speeds are compensated by shorter exposure duration $T_{i}$, which is, for example, 3 times lower for the speed of $5 \mathrm{~km} \cdot \mathrm{h}^{-1}$ compared to $15 \mathrm{~km} \cdot \mathrm{h}^{-1}$.

The generalized results of the speed influence on RMS VTV and $A(8)$ are given in Figures 3 and 4.

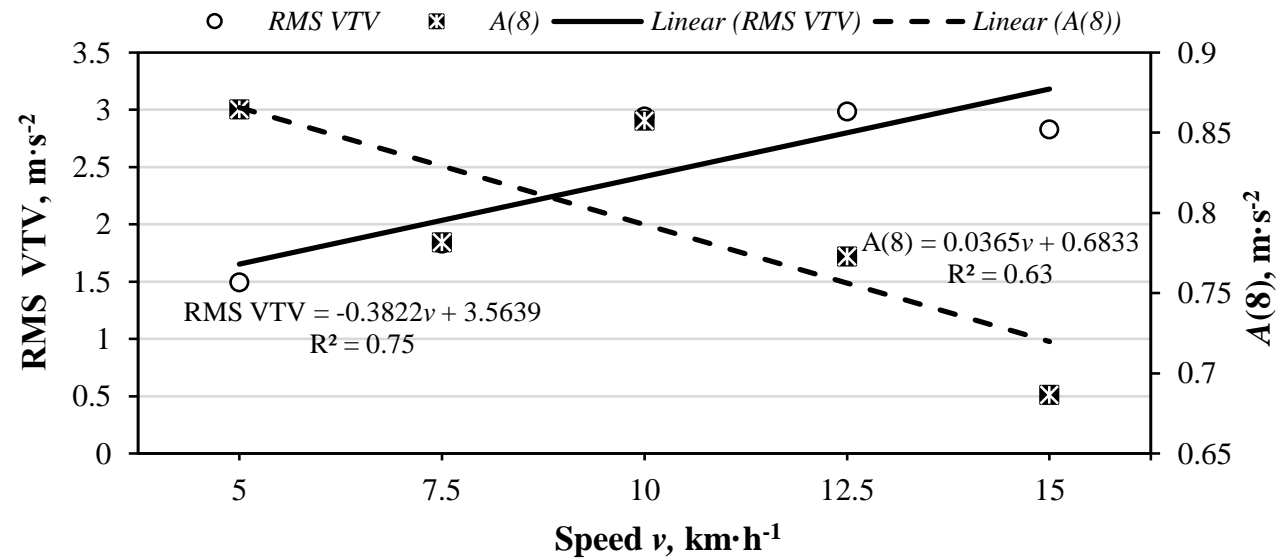

Fig. 3. Vibration RMS VTV and $A(8)$ dependence on the driving speed for empty travel operation

The results given in Fig. 3 show that the optimum driving speed by interrelating the measured RMS VTV acceleration and vibration exposure $A(8)$ can be described as follows:

$$
-0.3822 v+3.5639=0.0365 v+0.6833 .
$$

Intersection of these two equations represents the driving speed ( $v$ ), which is equal $\sim 8.4 \mathrm{~km} \cdot \mathrm{h}^{-1}$, and is optimum to reach the vibration exposure of $0.82 \mathrm{~m} \cdot \mathrm{s}^{-2}$ for the empty travel operation. These results can be seen in Fig. 4. 


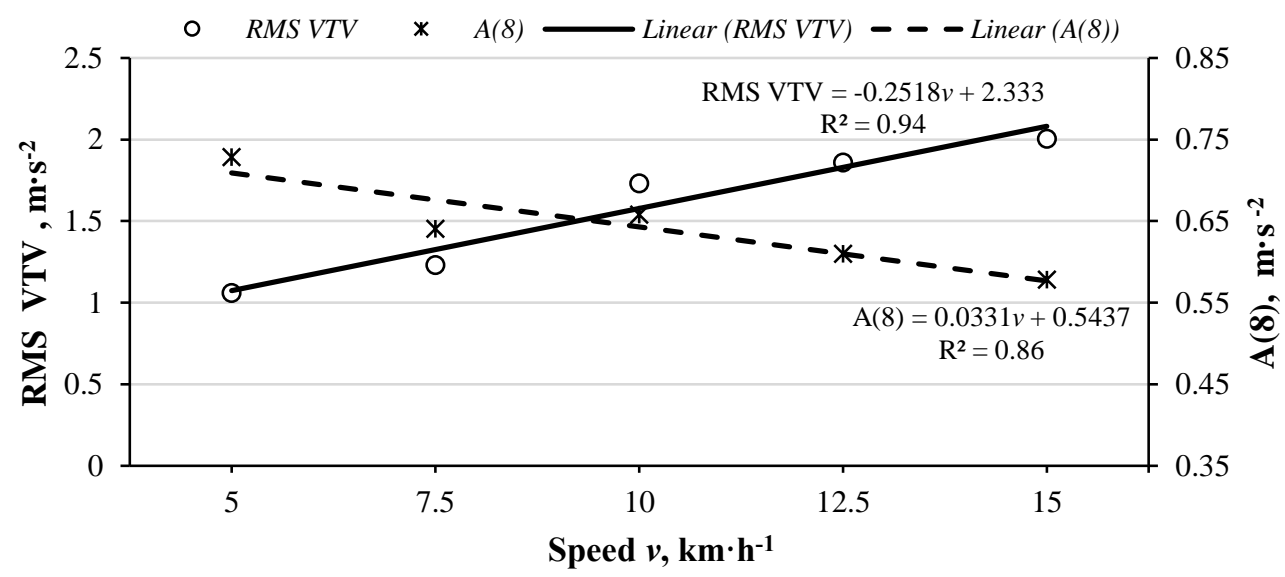

Fig. 4. Vibration RMS VTV and $A(8)$ dependence on the driving speed for full travel operation

The optimum driving speed for the optimum vibration exposure in full travel operation was $8.2 \mathrm{~km} \cdot \mathrm{h}^{-1}$ and was calculated as follows:

$$
-0.2518 v+2.333=0.0331 v+0.5437 .
$$

Similar results were calculated also for a shorter transportation distance, i.e. for total driving distance of $10 \mathrm{~km}$. These results show that optimum speed for empty transport was $8.6 \mathrm{~km} \cdot \mathrm{h}^{-1}$ and $7.6 \mathrm{~km} \cdot \mathrm{h}^{-1}$ for loaded transport, respectively.

Generalization from these results reveals that the vibration exposure of the forwarder operator can be optimized by appropriately selecting driving speed. Optimum speed for loaded transport was $\sim 8 \mathrm{~km} \cdot \mathrm{h}^{-1}$ and slightly higher for empty transport operations $\left(8.5 \mathrm{~km} \cdot \mathrm{h}^{-1}\right)$. As full and empty transport operations have higher RMS vibration acceleration values than loading/unloading, it is reasonable to follow these driving speed recommendations for driving on a haul road.

The results of WBV acceleration RMS VTV are slightly higher in our study in comparison with the results in other studies. The difference in RMS VTS values between full and empty transport operations ranged from $\sim 29$ to $\sim 40$ percent at various driving speeds. Rehn [3] reported the difference of 35 percent and the Poje [4] even a smaller difference of $\sim 20$ percent. This can be explained by the higher driving speeds in our study. However, general conclusion is that in areas with long transport distances the vibration exposure will increase as the movement time increases. None of the studies analysed the total vibration exposure, therefore, it is impossible to compare the $A(8)$ results, but as the RMS VTV values are similar for traveling and loading/unloading, the results are expected to be very similar, especially at the calculated optimum speeds.

An interesting finding in our study was that typical driving speed, selected by the operator at the present condition was $\sim 10 \mathrm{~km} \cdot \mathrm{h}^{-1}$. As the determined optimum speed for optimum $A(8)$ exposure was slightly lower than $10 \mathrm{~km} \cdot \mathrm{h}^{-1}$, this means that operators tend to drive faster than reasonably practicable from the perspective of the operator whole-body vibration exposure perspective. These results also show that lower back pain problems and other health problems caused by whole body vibration can be minimized by constantly monitoring the operator behaviour and selection of the driving speed in respect with the existing haul road conditions in the logging location.

\section{Conclusions}

1. The measured vibration total values in empty and full forwarder travel operations in the speed range from 7.5 to $15 \mathrm{~km} \cdot \mathrm{h}^{-1}$ show that VTV was higher by $29-40$ percent for empty travel in the speed range from 5.0 to $15.0 \mathrm{~km} \cdot \mathrm{h}^{-1}$. Additionally, the speed increase was a critical factor for the absolute value of whole-body vibration RMS VTV, which was $1.28 \mathrm{~m} \cdot \mathrm{s}^{-2}$ at the driving speed of $5 \mathrm{~km} \cdot \mathrm{h}^{-1}$ and increased to $2.4 \mathrm{~m} \mathrm{~s}^{-2}$ at speed of $15 \mathrm{~km} \cdot \mathrm{h}^{-1}$, respectively.

2. The calculated optimum speed for the driving forwarder in a haul road in full and empty travel operations ranged from 7.6 to $8.6 \mathrm{~km} \cdot \mathrm{h}^{-1}$. Forwarding at this speed is reasonable, as eight hour vibration exposure $A(8)$ for the total driving distance of $10 \mathrm{~km}$ per work shift will give the exposure less than $0.5 \mathrm{~m} \cdot \mathrm{s}^{-1}$ for full transport operations and $\sim 0.57 \mathrm{~m} \cdot \mathrm{s}^{-1}$ for empty transport. For longer 
transport distances (20 km per work shift) the operator vibration exposure would increase by 25 $30 \%$, respectively.

3. Operator WBV exposure and vibration acceleration values in full and empty forwarding operations can vary significantly at various driving speeds. The results suggest that WBV at various driving speeds should be constantly monitored under specific road conditions and long transportation distances. This could be a preventative action to avoid negative WBV effects on operators as forwarder drivers typically select faster driving than the optimum from the perspective of wholebody vibration exposure in transport operations.

\section{Acknowledgements}

This research has received funding from the European Union Horizon 2020 research and innovation programme under grant agreement No. 727883 .

\section{References}

[1] Berg S., Ersson B.T., Manner J. Distance driven and driving speed when forwarding during final felling in Central Sweden. J. For. Sci., vol. 65: 2019, pp. 183-194.

[2] Kumazawa Y., Fujita M., Yamasaki A., etc. Consideration about safety and efficient log transportation by forwarders. Journal of the Japan Forest Engineering Society, vol. 26: 2011, pp. 181-186.

[3] Rehn B., Lundström R., Nilsson L. etc. Variation in exposure to whole-body vibration for operators of forwarder vehicles - Aspects on measurement strategies and prevention. International Journal of Industrial Ergonomics, vol. 35, 2005, pp. 831-842.

[4] Poje A., Grigolato S., Potočnik I. Operator Exposure to Noise and Whole-Body Vibration in a Fully Mechanised CTL Forest Harvesting System in Karst Terrain. Croatian Journal of Forest Engineering, vol. 40, 2019, pp. 139-250.

[5] Tiernan D., Zeleke G., Owende P.M.O etc. Effect of Working Conditions on Forwarder Productivity in Cut-to-length Timber Harvesting on Sensitive Forest Sites in Ireland. Biosystems Engineering, vol. 87, 2004, pp. 167-177.

[6] Strandgard M., Mitchell R., Acuna M. Time consumption and productivity of a forwarder operating on a slope in a cut-to-length harvest system in a Pinus radiata D. Don pine plantation. Journal of Forest Science, vol. 63, 2017, pp. 324-330.

[7] Killen W., Eger T. Factors Affecting Operator Exposure to Whole-body Vibration. Position paper CRE-MSD 4164-6, Centre of Research Expertise for the Prevention of Musculoskeletal Disorders [online] [02.02.2021]. Available at: https://uwaterloo.ca/centre-of-research-expertise-for-theprevention-of-musculoskeletal-disorders/sites/ca.centre-of-research-expertise-for-the-preventionof-musculoskeletal-disorders/files/uploads/files/4164-6_position_paper_2016_ -_eger_killen_wbv.pdf

[8] Geiger C., Geimer M. Sustainable Logging Process by a Forwarder with an Innovative HydroPneumatic Suspension. The Sixteenth Scandinavian International Conference on Fluid Power, May 22-24, 2019, Tampere, Finland.

[9] Rehn B., Lundström R., Nilsson L., etc. Variation in exposure to whole-body vibration for operators of forwarder vehicles - aspects on measurement strategies and prevention. International Journal of Industrial Ergonomics, vol. 35(9), 2005, pp. 831-842.

[10] ISO 2631-1 (1997). Evaluation of Human Exposure to Whole-body Vibration-Part 1: General Requirements.

[11] European Union (2002) Directive 2002/44/EC of the European Parliament and of the Council of 25 June 2002 on the minimum health and safety requirements regarding the exposure of workers to the risks arising from physical agents (vibration) (sixteenth individual Directive within the meaning of Article 16(1) of Directive 89/391/EEC. Official Journal of the European Communities L 177. 